\title{
Serum myeloperoxidase level is increased in heavy smokers
}

\author{
André B. Martins ${ }^{1}$, Valdecir F. Ximenes ${ }^{2}$, Luiz Marcos da Fonseca ${ }^{1}$ \\ ${ }_{1}^{1}$ Departamento de Análises Clínicas, Faculdade de Ciências Farmacêuticas, Universidade Estadual Paulista-UNESP, Araraquara, Brasil \\ ${ }^{2}$ Departamento de Química, Faculdade de Ciências, Universidade Estadual Paulista-UNESP, Bauru, Brasil \\ Email: fonseclm@,fcfar.unesp.br
}

Received 18 January 2013; revised 28 February 2013; accepted 8 March 2013

\begin{abstract}
Raised myeloperoxidase (MPO) serum levels are associated with endothelial dysfunction and cigarette smoking is a risk factor for cardiovascular diseases. Since myocardial infarction is associated with leukocytosis and smokers present increased levels of neutrophils, here we hypothesized that the levels of serum MPO in smokers could be also raised. We carried out a study on sixty eight adult healthy volunteers. The control group consisted of thirty four nonsmokers and the test group was thirty four heavy smokers. The hemogram, interleukin-8 (IL-8) and MPO serum levels were measured. Neutrophil, monocyte and lymphocyte counts were higher $(p<0.05)$ and the serum levels of interleukin-8 (IL-8) and MPO were fourfold higher in smokers than in non-smokers $(\mathrm{n}=34, \mathrm{p}<0.05)$. This result correlated perfectly with the increased neutrophil count and IL-8 serum level that characterize smoking subjects. We propose that the high level of serum MPO could be directly involved in the higher prevalence of coronary artery diseases among heavy smokers.
\end{abstract}

Keywords: Smokers; Neutrophils; IL-8; Myeloperoxidase; Hypochlorous Acid; Atherosclerosis

\section{INTRODUCTION}

Myeloperoxidase (MPO) is a heme enzyme abundantly expressed by neutrophils. It is the catalyst responsible for production of the microbicide hypochlorous acid $(\mathrm{HOCl})$ by the oxidation of chloride $\left(\mathrm{Cl}^{-}\right)$by hydrogen peroxide $\left(\mathrm{H}_{2} \mathrm{O}_{2}\right)$ [1].This enzymatic pathway is a fundamental part of the innate immune response and is triggered when these cells are activated by noxious stimuli [2]. However, $\mathrm{HOCl}$ can also take part in deleterious oxidative processes associated with chronic inflammatory diseases, including atherosclerosis $[3,4]$. In addition to that, there is substantial evidence that MPO plays an important role in the pathogenesis of cardiovascular diseases [5-7]. The discovery that the blood serum level of MPO is a bio- marker for the prognosis of coronary artery diseases has opened up a new area of research with immediate utility in clinical practice [8-11].

It is well established, scientifically and clinically, that smokers are significantly more susceptible to a variety of diseases, including coronary artery diseases [12]. Smokers also have increased blood counts of neutrophils and monocytes [13], which are the main endogenous sources of MPO. Moreover, chronic exposure to cigarette smoke causes increased production and secretion of metalloproteinase by macrophages and proteolytic enzymes by neutrophils [14]. Hence, we hypothesized that the blood serum level of MPO in tobacco smokers might also be elevated and could be involved in their susceptibility to cardiovascular diseases.

\section{MATERIALS AND METHODS}

Blood donors: The study included sixty eight adult healthy volunteers (aged 20 to 67 years). The control group consisted of thirty four non-smokers (15 women and 19 men) and the study group was thirty four heavy smokers (more than two packs/day, 16 women and 18 men). None of the volunteers reported the use of medication. All subjects gave written informed consent for examinations and participation in the study. The study was approved by the Faculty research ethics committee (Comite de Etica em Pesquisa FCFAR/UNESP n 24/ 2009).

Blood samples, hematological and biochemical analysis: Blood samples (totaling $8 \mathrm{~mL}$ ) were obtained by venipuncture. The first $4 \mathrm{~mL}$ was collected in an EDTA tube and used for hematological analysis. The Other 4 $\mathrm{mL}$ was collected without anticoagulant and used to determine serum MPO and interleukin-8. The complete hemogram was performed in a Coulter STKS hematological autoanalyzer (Miami, USA). Blood serum was separated by centrifugation at $400 \times \mathrm{g}$ for 20 minutes and stored at $-80^{\circ} \mathrm{C}$ until analysis. The serum level of MPO was measured by MPO-EIA (InnoZyme Calbiochem, Merck KgaA, Darmstadt, Germany) and serum IL-8 was measured by ELISA (RayBiotech, Norcross GA, USA) following the manufacturer's instructions. The blood sam- 
ples were assayed in duplicate and the results averaged.

\section{RESULTS AND DISCUSSIONS}

Leukocytosis is the main immune alteration observed in the blood system of smokers and a common feature is the increased number of neutrophils in blood, sputum and bronchial biopsies [14]. The number of peripheral blood neutrophils correlated with the smoking status. Thus, a high smoking rate was associated with appreciable increases counts; former smokers, with less than 5 years abstinence, still demonstrated elevated counts and those who had abstained for more than 5 years had counts comparable to those in people who had never smoked [15]. In corroboration, we found in this study that neutrophil, monocyte and lymphocyte counts are higher in smokers than in non-smokers (Table 1).

The cause of the neutrophilia has not yet been totally clarified, but nicotine has been implicated in the stimulation of neutrophils to produce interleukin-8 (IL-8), which is a potent neutrophil chemo-attractant and activator. IL-8 causes mild to moderate neutrophilia and its blood level is positively correlated with the degree of cigarette smoking [16]. The pathway for nicotine-stimulated production of IL-8 has been linked to nicotinic acetylcholine receptors (nAChRs) via the generation of peroxynitrite and subsequent NF-kappaB activation [16]. In addition, it has recently been demonstrated that dendritic cells exposed to cigarette smoke extract release IL-8 [17]. Chronic cigarette smoking also stimulates the bone marrow, increases the size of the mitotic and postmitotic pools of neutrophils and reduces the time that neutrophils spend in the postmitotic pool in the marrow [18]. Corroborating these findings, here we found that the serum level of IL-8 was about 4-fold higher in smokers than in non-smokers (Figure 1).

MPO, which constitutes up to $5 \%$ of the dry weight of neutrophils [19], may play a pivotal role in atherogenesis [5-7]. Hypochlorous acid, the endogenous product of MPO-catalyzed oxidation of the chloride anion, has been implicated as one of the major reactive intermediates in-

Table 1. Peripheral blood leucocytes.

\begin{tabular}{ccc}
\hline & \multicolumn{2}{c}{ Leucocytes $($ Cells $/ \mathrm{L})$} \\
\cline { 2 - 3 } & Smokers $(\mathrm{n}=34)$ & Non-Smokers $(\mathrm{n}=34)$ \\
\hline Neutrophils & $6002 \pm 291^{\#}$ & $3731 \pm 144$ \\
Monocytes & $639 \pm 44^{\#}$ & $481 \pm 29$ \\
Lymphocytes & $2281 \pm 92^{\#}$ & $2023 \pm 86$ \\
Eosinophils & $206 \pm 25$ & $191 \pm 24$ \\
Basophils & $58 \pm 9$ & $55 \pm 8$ \\
\hline
\end{tabular}

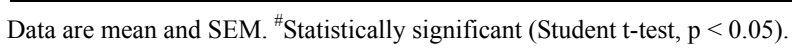

volved in the oxidation of low-density lipoproteins (LDL), which is an early event in atherosclerosis $[3,4]$. The essential reverse cholesterol transport by high density lipoprotein (HDL) might also be compromised, since this lipoprotein is an in vivo target for MPO-catalyzed oxidation, impairing its cardioprotective and anti-inflammatory capacity $[5,20,21]$. MPO also impairs the ATP-binding cassette transporter AI (ABCA1)-dependent cholesterol efflux by promoting methionine oxidation and sitespecific tyrosine chlorination of apolipoprotein A-I [22]. Moreover, elevated MPO levels are associated with endothelial dysfunction [23] and acute myocardial infarction is frequently associated with leukocytosis and raised peripheral neutrophil counts [24]. The influence of tobacco smoke on human health is still an important problem worldwide. Here, for the first time, it has been demonstrated that smokers exhibit an increased level of blood serum MPO (Figure 2). This result correlates perfectly with the increased in neutrophil count and IL-8 serum level that characterize smoking subjects.

\section{CONCLUSION}

Taking into account the widely-accept deleterious role of MPO in atherosclerosis [5-7] and the raised values of MPO serum level [8-11] and neutrophil counts [24-26] as predictive factors for cardiovascular events, we propose that the high level of serum MPO could be directly

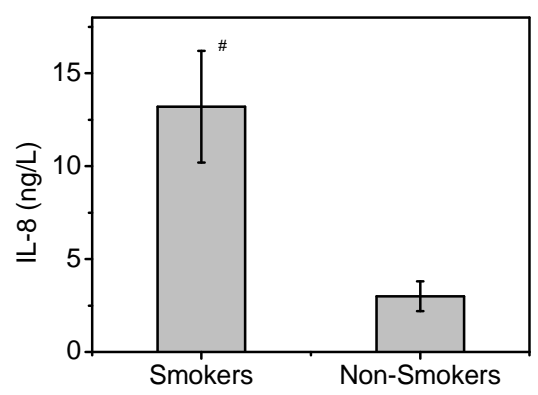

Figure 1. Serum level of IL-8. The results are mean and SEM $(\mathrm{n}=34)$. " Statistically significant (Student t-test, $\mathrm{p}<0.001$ ).

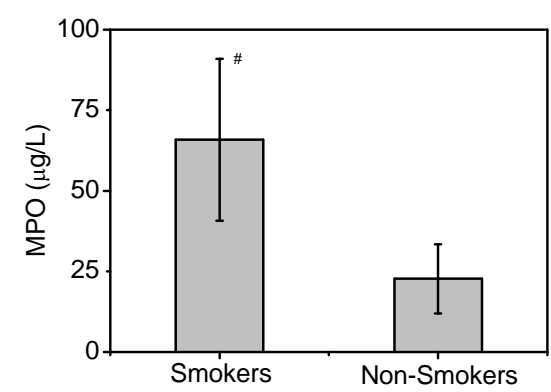

Figure 2. Serum level of MPO. The results are mean and SEM $(\mathrm{n}=34)$. ${ }^{\text {SStatistically }}$ significant (Student t-test, $\mathrm{p}<0.001$ ). 


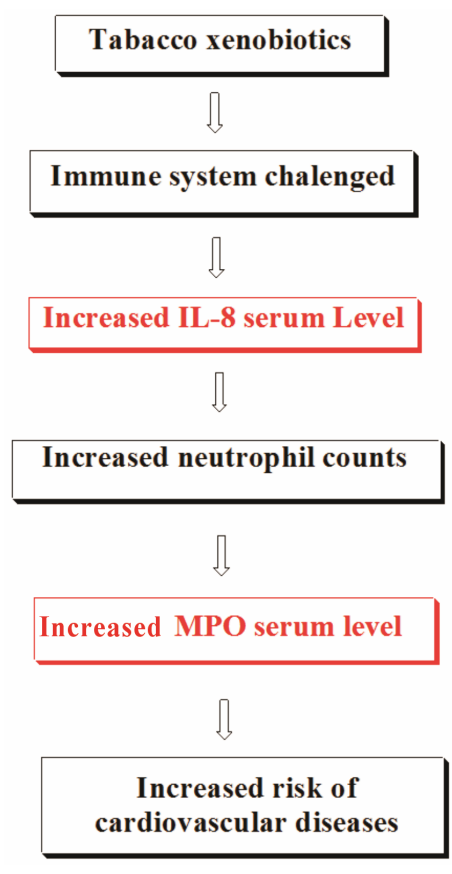

Scheme 1. Proposal for the correlation among smoking, increased neutrophil counts, augmented MPO serum level and increased coronary diseases in smokers subjects.

involved in the higher prevalence of coronary artery diseases among smokers $[27,28]$. Scheme 1 presents our proposal for the correlation among smoking, increased neutrophil counts, augmented MPO serum level and increased coronary diseases in smokers.

\section{ACKNOWLEDGEMENTS}

This study was supported by Fundação de Amparo a Pesquisa do Estado de São Paulo (FAPESP) and Conselho Nacional de Desenvolvimento Científico e Tecnológico (CNPq), Brazil.

\section{REFERENCES}

[1] Shepherd, V.L. (1986) The role of the respiratory burst of phagocytes in host defense. Seminars in Respiratory Infections, 1, 99-106.

[2] Klebanoff, S.J. (2005) Myeloperoxidase: Friend and foe. Journal Leukocytes Biology, 77, 598-625. doi:10.1189/jlb.1204697

[3] Spickett, C.M. (2007) Chlorinated lipids and fatty acids: An emerging role in pathology. Pharmacology Therapy, 115, 400-409. doi:10.1016/j.pharmthera.2007.06.002

[4] Lau, D. and Baldus, S. (2006) Myeloperoxidase and its contributory role in inflammatory vascular disease. Pharmacology Therapy, 111, 16-26. doi:10.1016/j.pharmthera.2005.06.023

[5] Shao, B., Oda, M.N., Oram, J.F. and Heinecke, J.W. (2010) Myeloperoxidase: An oxidative pathway for gen- erating dysfunctional high-density lipoprotein. Chemical Research Toxicology, 23, 447-454.

doi:10.1021/tx9003775

[6] Chantepie, S., Malle E., Sattler, W., Chapman, M.J. and Kontush, A. (2009) Distinct HDL subclasses present similar intrinsic susceptibility to oxidation by $\mathrm{HOCl}$. Archives Biochemistry Biophysics, 487, 28-35. doi:10.1016/j.abb.2009.05.005

[7] Van der Veen, B.S., de Winther, M.P. and Heeringa, P. (2009) Myeloperoxidase: Molecular mechanisms of action and their relevance to human health and disease. Antioxidant Redox Signaling, 11, 2899-2937. doi:10.1089/ars.2009.2538

[8] Baldus, S., Heeschen, C., Meinertz, T., Zeiher, M., Eiserich, J.P., Münzel T., Simoons M.L. and Hamm, C.W. (2003) Myeloperoxidase serum levels predict risk in patients with acute coronary syndromes. Circulation, $\mathbf{1 0 8}$, 1440-1445. doi:10.1161/01.CIR.0000090690.67322.51

[9] Roman, R.M., Camargo, P.V., Borges, F.K., Rossini, A.P. and Polanczyk, C.A. (2010) Prognostic value of myeloperoxidase in coronary artery disease: Comparison of unstable and stable angina patients. Coronary Artery Disease, 21, 129-136. doi:10.1097/MCA.0b013e328333f50d

[10] Pawlus, J., Hołub, M., Kożuch, M., Dąbrowska, M. and Dobrzycki, S. (2010) Serum myeloperoxidase levels and platelet activation parameters as diagnostic and prognostic markers in the course of coronary disease. International Journal Laboratory Hematology, 32, 320-328. doi:10.1111/j.1751-553X.2009.01203.x

[11] Wong, N.D., Gransar, H., Narula, J., Shaw, L., Moon, J.H., Miranda-Peats, R., Rozanski, A., Hayes, S.W., Thomson, L.E., Friedman, J.D. and Berman, D.S. (2009) Myeloperoxidase, subclinical atherosclerosis, and cardiovascular disease events. JACC Cardiovascular Imaging, 2, 1093-1099. doi:10.1016/j.jcmg.2009.05.012

[12] Doll, R. and Peto, R. (1976) Mortality in relation to smoking: 20 years observation on male British doctors. British Medical Journal, 2, 1525-1561. doi:10.1136/bmj.2.6051.1525

[13] Bridges, R.B., Wyatt, R.J. and Rehm, S.R. (1885) Effect of smoking on peripheral blood leucocytes. European Journal Respiratory Diseases, 661, 24-33.

[14] Gorska, K., Krenke, R., Domagala-Kulawik, J., Korczynski, P., Nejman-Gryz, P., Kosciuch, J., Hildebrand, K. and Chazan, R. (2008) Comparison of cellular and biochemical markers of airway inflammation in patients with mild-to-moderate asthma and chronic obstructive pulmonary disease: An induced sputum and bronchoalveolar lavage fluid study. Journal Physiology Pharmacology, 59, 271-283.

[15] Parry, H., Cohens, S. and Schlarb, J.E. (1997) Smoking, alcohol consumption and leucocytes counts. American Journal Clinical Pathology, 107, 64-67.

[16] Iho, S., Tanaka, Y., Takauji, R., Kobayashi, C., Muramatsu, I., Iwasaki, H., Nakamura, K., Sasaki, Y., Nakao, K. and Takahashi, T. (2003) Nicotine induces human neutrophils to produce IL-8 through the generation of peroxynitrite and subsequent activation of NF-kappaB. Journal Leukocytes Biology, 74, 942-951. 
doi:10.1189/jlb.1202626

[17] Vassallo, R., Kroening, P.R., Parambil, J. and Kita, H. (2008) Nicotine and oxidative cigarette smoke constituents induce immune-modulatory and pro-inflammatory dendritic cell responses. Molecular Immunology, 45, 33213329. doi:10.1016/j.molimm.2008.04.014

[18] Terashima, T., Wiggs, B., English, D., Hogg, J.C. and Van Eeden, S.F. (1997) The effect of cigarette smoking on the bone marrow. American Journal Respiratory Critical Care Medicine, 155, 1021-1026.

[19] Schultz, J. and Kaminker, K. (1962) Myeloperoxidase of leukocyte of normal blood content and localization. Archives Biochemistry Biophysics, 98, 465-471. doi:10.1016/0003-9861(62)90321-1

[20] Undurti, A., Huang, Y., Lupica, J.A., Smith, J.D., DiDonato, J.A. and Hazen, S.L. (2009) Modification of high density lipoprotein by myeloperoxidase generates a proinflammatory particle. Journal Biological Chemistry, 284, 30825-30835. doi:10.1074/jbc.M109.047605

[21] Malle, E., Marsche, G., Panzenboeck, U. and Sattler, W. (2006) Myeloperoxidase-mediated oxidation of high-density lipoproteins: Fingerprints of newly recognized potential proatherogenic lipoproteins. Archives Biochemistry Biophysics, 445, 245-255. doi:10.1016/j.abb.2005.08.008

[22] Shao, B., Oda, M.N., Bergt, C., Fu, X., Green, P.S., Brot, N., Oram, J.F. and Heinecke, J.W. (2006) Myeloperoxidase impairs ABCA1-dependent cholesterol efflux through methionine oxidation and site-specific tyrosine chlorination of apolipoprotein A-I. Journal Biological Chemistry, 281, 9001-9004. doi:10.1074/jbc.C600011200

[23] Vita, J.A., Brennan, M.L., Gokce, N., Mann, S.A., Goor- mastic, M., Shishehbor, M.H., Penn, M.S., Keaney, J.F. and Hazen, S.L. (2004) Serum myeloperoxidase levels independently predict endothelial dysfunction in humans. Circulation, 110, 1134-1139. doi:10.1161/01.CIR.0000140262.20831.8F

[24] Green, S.M., Vowels, J., Waterman, B., Rothrock, S.G., and Kuniyoshi, G. (1996) Leukocytosis: A new look at an old marker for acute myocardial infarction. Academy Emergence Medicine, 3, 1034-1041. doi:10.1111/j.1553-2712.1996.tb03350.x

[25] Angeli, F., Angeli, E., Ambrosio, G., Mazzotta, G., Reboldi, G. and Verdecchia, P. (2010) Neutrophil count for the identification of postmenopausal hypertensive women at increased cardiovascular risk. Obstetric Gynecology, 115, 695-703. doi:10.1097/AOG.0b013e3181d53df6

[26] Gibson, P.H., Cuthbertson, B.H., Croal, B.L., Rae, D., El-Shafei, H., Gibson, G., Jeffrey, R.R., Buchan, K.G. and Hillis, G.S. (2010) Usefulness of neutrophil/lymphocyte ratio as predictor of new-onset atrial fibrillation after coronary artery bypass grafting. American Journal Cardiology, 105, 186-191. doi:10.1016/j.amjcard.2009.09.007

[27] Nicita-Mauro, V., Maltese, G., Nicita-Mauro, C., Lasco, A. and Basile, G. (2010) Non smoking for successful aging: Therapeutic perspectives. Current Pharmaceutical Design, 16, 775-782. doi:10.2174/138161210790883552

[28] Luo, Y., Li, X., Li, J., Wang, X., Qiao, Y., Hu, D., Merriam, P.A. and Ma, Y. (2010) Combined effects of smoking and peripheral arterial disease on all-cause and cardiovascular disease mortality in a Chinese male cohort. Journal Vascular Surgery, 51, 673-678. doi:10.1016/j.jvs.2009.09.024 